\title{
Basic Analysis of a Steel Structure for Extreme Wind Loads
}

\author{
Mohammed Faruqi, Ateeq Mohammed Abdul, Francisco Aguiniga, Breanna Bailey
}

Department of Civil and Architectural Engineering, Texas A \& M University-Kingsville, Kingsville, USA

\section{Email address:}

m-faruqi@tamuk.edu (M. Faruqi)

\section{To cite this article:}

Mohammed Faruqi, Ateeq Mohammed Abdul, Francisco Aguiniga, Breanna Bailey. Basic Analysis of a Steel Structure for Extreme Wind Loads. Engineering and Applied Sciences. Vol. 6, No. 4, 2021, pp. 74-81. doi: 10.11648/j.eas.20210604.12

Received: August 15, 2021; Accepted: August 30, 2021; Published: September 6, 2021

\begin{abstract}
In recent years, there has been an increase in United States (US) population and hence subsequently the increase in construction. Hurricanes are natural disaster and have a high probability rate of impact in the US. This is because the US has an extensive shoreline. Accordingly, US has experienced a number of hurricanes and its after effects are still evident. Therefore, there is a need to study these hurricanes and produce a better hurricane resistant design. In this basic work, we used hurricane intensity loads to study the effect of a hurricane on a typical shopping mall located in South Texas region using RISA-3D (Rapid Interactive Structural Analysis - 3 Dimensions) software along with the combination of design specifications from American Society of Civil Engineers (ASCE) and American Institute of Steel Construction-Load-Resistance and Factor Design (AISC-LRFD). The design factors for the calculation of the wind pressure were obtained from the ASCE manual and the members were selected from AISC-LRFD. A total of six loading cases were studied in this project namely: uniformly distributed and concentrated loads with no brace, two braces and four brace combinations. It was found that member M1 with no brace and four braces respectively produced the largest and smallest moments and member M4 with no brace and four braces respectively produced the highest and lowest deflections. The results from the basic analysis showed that we need to address controlling moments and deflections in critical members for a better hurricane resistant design.
\end{abstract}

Keywords: Hurricanes, Design, Moments, Deflections, Software

\section{Introduction}

Tropical storms, hurricanes and tornadoes are natural disaster causing phenomenon which have a high probability rate of impact in the United States (US) [1] This is due to the tropical weather, and also due to the fact that the US has an extensive shoreline [1]. The US is affected by at least a couple of these storms each year on a regular basis [1]. Further, The US has experienced a massive influx in its population for the past few decades [1]. This population increase has resulted in a proliferation of various types of construction, including, shopping centers, residential buildings, condominiums, hotels and motels. This has resulted in increased potential of storm-induced damage [1].

Experience with hurricanes in the US has established the importance of wind to the performance of buildings [2-10]. Compromising the buildings due to hurricane winds leads to major economic loss through damage to building content, possible failure of structural systems, and a hazard to building occupants [1]. Hence, it is important that the building design process address these important hurricane effects, which affect building performance [1].

The importance of wind protection to building performance in hurricanes became quite evident to experts involved in the building industry following the devastating effects of Hurricane Andrew [1]. This hurricane created an enormous amount of damage, the impact of Hurricane Andrew, the costliest hurricane at the time, in US prompted reviews by several local, state and federal agencies [1]. Since then, engineers and building officials have had to address issues concerning building design to account for enhanced turbulent wind pressures by these winds [1].

\section{Defining the Problem and Review of Wind Loads}

The main goal of this work was to analyze a typical shopping center located in South Texas subjected to hurricane intensity loads using RISA-3D [11] along with the combination of design specifications from American Society of Civil Engineers (ASCE) [12] and American Institute of 
Steel Construction-Load-Resistance and Factor Design (AISC-LRFD) [13]. The design factors for the calculation of the wind pressure were obtained from [12] and the members were selected from the steel manual [13]. Since the structure under consideration is located in South Texas region, it is prone to heavy wind loads due to hurricanes. The wind speed selected in this work was $230 \mathrm{mph}$ [14]. This helped identify critical members in the structure with the aim of producing better hurricane resistant design.

\subsection{Geometrical and Geographical Considerations}

Figure 1 shows a generalized shopping mall under consideration. The mall is located in a hurricane prone area. This mall is subjected to wind loads of $230 \mathrm{mph}$.

The wind loads are an important feature of the design process. The design of the project consisted of determining design loads and selection of members based on the design moments.

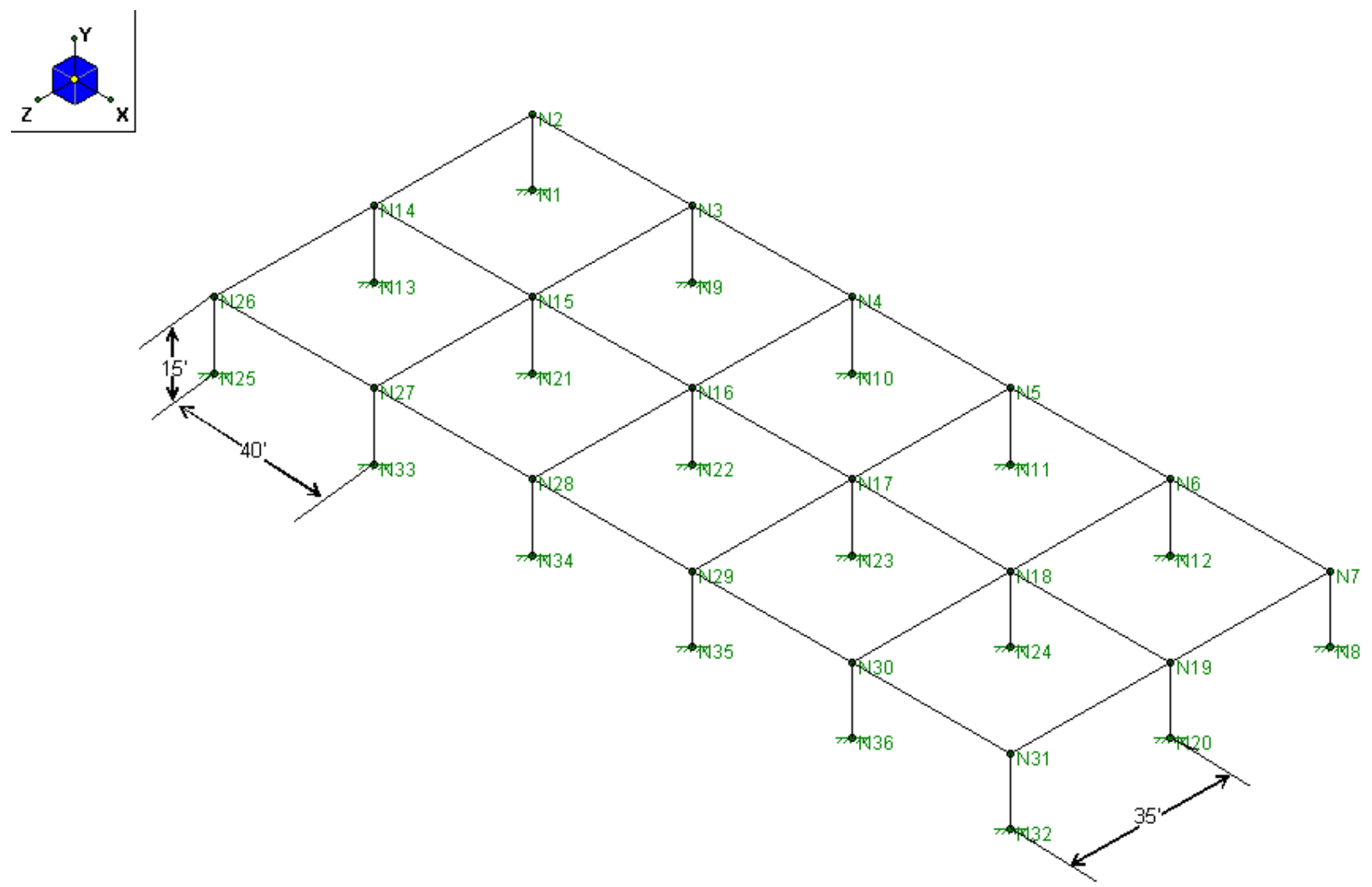

Figure 1. Generalized Shopping Mall.

\subsection{Wind Loads}

Wind loads are extremely destructive and their complete behavior is very difficult to predict. This is due to many factors and the uncertainties associated with them. Some of the factors include topography, building type, nature of air flow etc. ASCE-7 Standard [12] allows two procedures for determining the minimum design wind loads:

1. Analytical procedure, and

2. Wind tunnel testing procedure.

This project utilized the analytical procedure to calculate the wind loads. This is because the wind tunnel procedure is used for designing structures with irregular geometrical or special site locations, such as high-rise buildings and suspension bridges.

The wind load computed using the analytical approach is based on an approximate wind pressure derived by treating the air as perfect fluid and when the wind strikes an object in its path, the kinetic energy of the moving particles is converted to pressure $q_{s}$ which is given by: $\mathrm{q}_{\mathrm{s}}=\mathrm{mV}^{2} / 2, \mathrm{~m}=$ the mass density of air, and $\mathrm{V}=$ wind velocity.

\subsection{Effect of Topography on Wind Pressure}

Figure 2 shown below implies that the wind pressure increases with elevation above the ground.

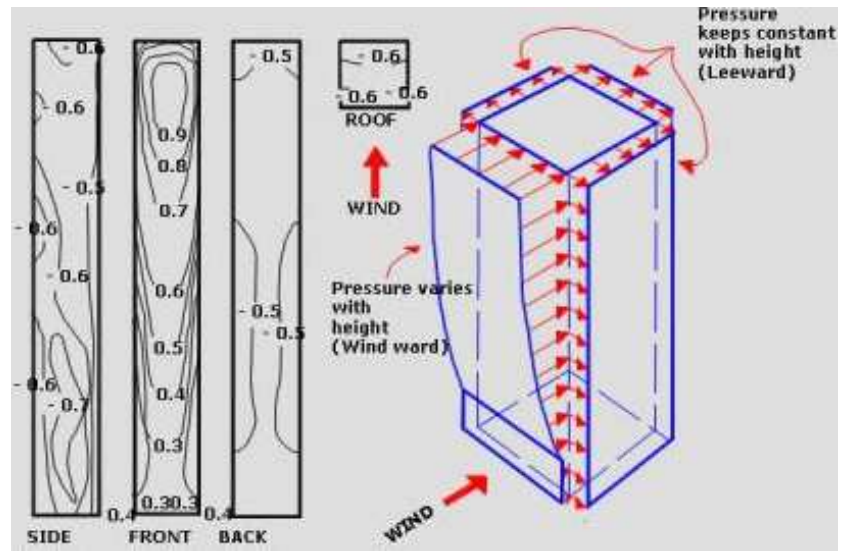

Figure 2. Profile of Wind Pressure on a Structure [15]. 


\subsection{Effect of Building Type on Wind Pressure}

Wind is like a fluid, objects submerged in flowing air will generate a complex flow pattern depending, amongst other things, on the shape of the object. For instance, consider a dolphin; its shape produces the least resistance to the flowing water because pressure is smallest when the object is streamlined. However, pressure is greatest for blunt or concave objects because they do not allow the air to pass smoothly around. Wind flowing past a building produces pressure on vertical windward surfaces, suction on sloping windward surfaces (depending on the slope), suction on the flat side and leeward surfaces. This analytical approach does not include allowances for cross-wind loading or vortex shedding.

\subsection{Equation for Predicting Design Velocity Pressures}

Treating the air as perfect fluid, the pressure $q_{\mathrm{s}}$ is transformed into an approximate wind pressure $q_{z}$.

$$
\mathrm{q}_{\mathrm{z}}=0.00256 \mathrm{~V}^{2} \mathrm{~K}_{\mathrm{D}} \mathrm{K}_{\mathrm{Z}} \mathrm{K}_{\mathrm{ZT}} \mathrm{I}
$$

Where,

$\mathrm{M}=$ The mass density of air is taken at $15^{\circ} \mathrm{C}$ at sea level

$\mathrm{V}=$ Wind velocity measured at $33 \mathrm{ft}$ from the ground at 3second gust, in mph. This is associated with an annual probability of 0.02 of being equaled or exceeded

$\mathrm{K}_{\mathrm{z}}=$ Velocity pressure exposure evaluated at height $\mathrm{z}$ above the ground

$\mathrm{K}_{\mathrm{d}}=$ Wind directionality factor

$\mathrm{K}_{\mathrm{zt}}=$ Topographic factor

$\mathrm{I}=$ Importance factor

The design wind speed for this research is $230 \mathrm{mph}$ which represents category 4 storm (Table 1). The coefficients in the above equation were evaluated using the code [12]. The importance factor I is assumed to be 1.0 for research purposes, the velocity pressure exposure evaluated at a height $\mathrm{Z}$ was taken as 0.85 for the exposure $\mathrm{C}$. The velocity pressure was calculated using the constants described above and came around 115 psf.

Table 1. Saffir-Simpson scale for hurricane categories [14].

\begin{tabular}{llll}
\hline Hurricane category & Velocity $(\mathbf{m p h})$ & Pressure $(\mathbf{m b})$ & damage \\
\hline 1 & $120-150$ & $>980$ & minimum \\
2 & $150-175$ & $965-980$ & moderate \\
3 & $175-210$ & $945-965$ & extensive \\
4 & $210-250$ & $920-945$ & extreme \\
5 & $>250$ & $<920$ & catastrophic \\
\hline
\end{tabular}

The $C_{p}$ values for roof pressure depends on the degree of the slope, the structure under analysis has a 0 slope and the ratio of $h / L$ is greater than 1 and is also greater than $h / 2$. Hence, the value of $C_{p}$ for the roof came out to -0.7 and -1.3 , to make things easy the average of the two values is considered. After taking all the conditions into consideration the wind pressure on the structure from all the sides was tabulated in Table 2. This pressure is later used to determine the uniformly distributed load acting on the frame by multiplying it with the area.
Table 2. Pressure intensities.

\begin{tabular}{llll}
\hline Pressure & Windward & Leeward & Side \\
\hline $\mathrm{P}(\mathrm{psf})$ & 95 & -11 & 37 \\
\hline
\end{tabular}

\subsection{Design Wind Pressure}

The design wind pressure for main wind force resisting system of the buildings was determined using the following equation [12]:

$$
\mathrm{P}=\mathrm{q}^{*} \mathrm{G}^{*} \mathrm{C}_{\mathrm{P}}-\mathrm{q}_{\mathrm{h}}\left(\mathrm{GC}_{\mathrm{pi}}\right)
$$

Where,

$\mathrm{q}=\mathrm{q}_{\mathrm{z}}$ for wind ward walls elevated at height $\mathrm{z}$ above the ground

$\mathrm{q}=\mathrm{q}_{\mathrm{h}}$ for leeward walls, side walls, and roofs elevated at height $\mathrm{h}$

$\mathrm{G}=$ gust effect factor

$\mathrm{C}_{\mathrm{p}}=$ external pressure coefficient

$\left(\mathrm{GC}_{\mathrm{p}}\right)=$ internal pressure coefficient

$\mathrm{P}=$ velocity pressure

The value of $\mathrm{G}$ was taken as 0.85 as provided in clause 6.5.8 of [12], $\mathrm{C}_{\mathrm{p}}$ values for wall and roof pressure were evaluated from [12] and $\mathrm{GC}_{\mathrm{p}}$ value from the same reference as well.

\section{Basic Description of RISA-3D and Steps Required}

RISA-3D [11] is a general purpose 3-dimensional analysis and design program. This program has been developed to make the definition, solution and modification of $3 \mathrm{D}$ structural models as fast and easy as possible [11]. Analysis, up to and including calculation of maximum deflections and stresses, may be carried out on structures constructed of any material or combination of materials. Complete steel and wood designs are also included in the program [11].

Steps Required for Analyzing the Frame

1) Start a new model option, define the coordinates, material, type of load, load pattern etc, and type of member involved using the RISA-3D spread.

2) Develop the frame using the predefined members either graphically or using the spread sheets available, RISA recommends graphical development of the frame since we have a better picture of the frame.

3) Applying the loads on the frame under the given load condition, in our case we are analyzing the frame for wind loads so our load condition is wind load.

4) Analyze the frame and review the results by clicking at the respective spread sheet provided by the software, i.e, moments, deflections, and forces.

\section{Computations and Comparison}

In this work we studied six cases. The cases with their respective images are shown below. The frame with the most stable analysis may be used for field work. 


\subsection{Case 1: Distributed Load and No Brace}

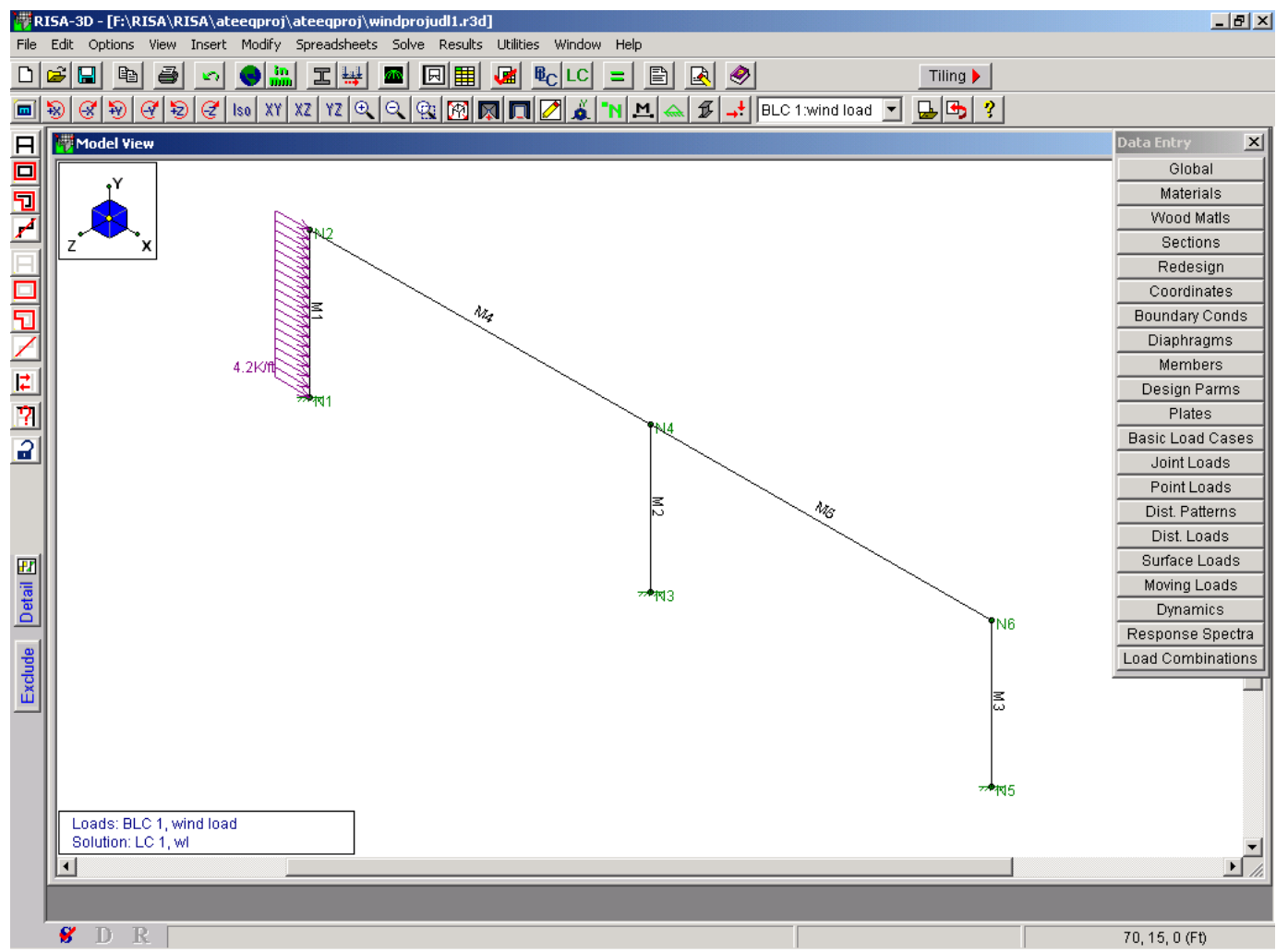

Figure 3. Basic Frame with Uniformly Distributed Wind Load.

\subsection{Case 2: Concentrated Load and No Brace}

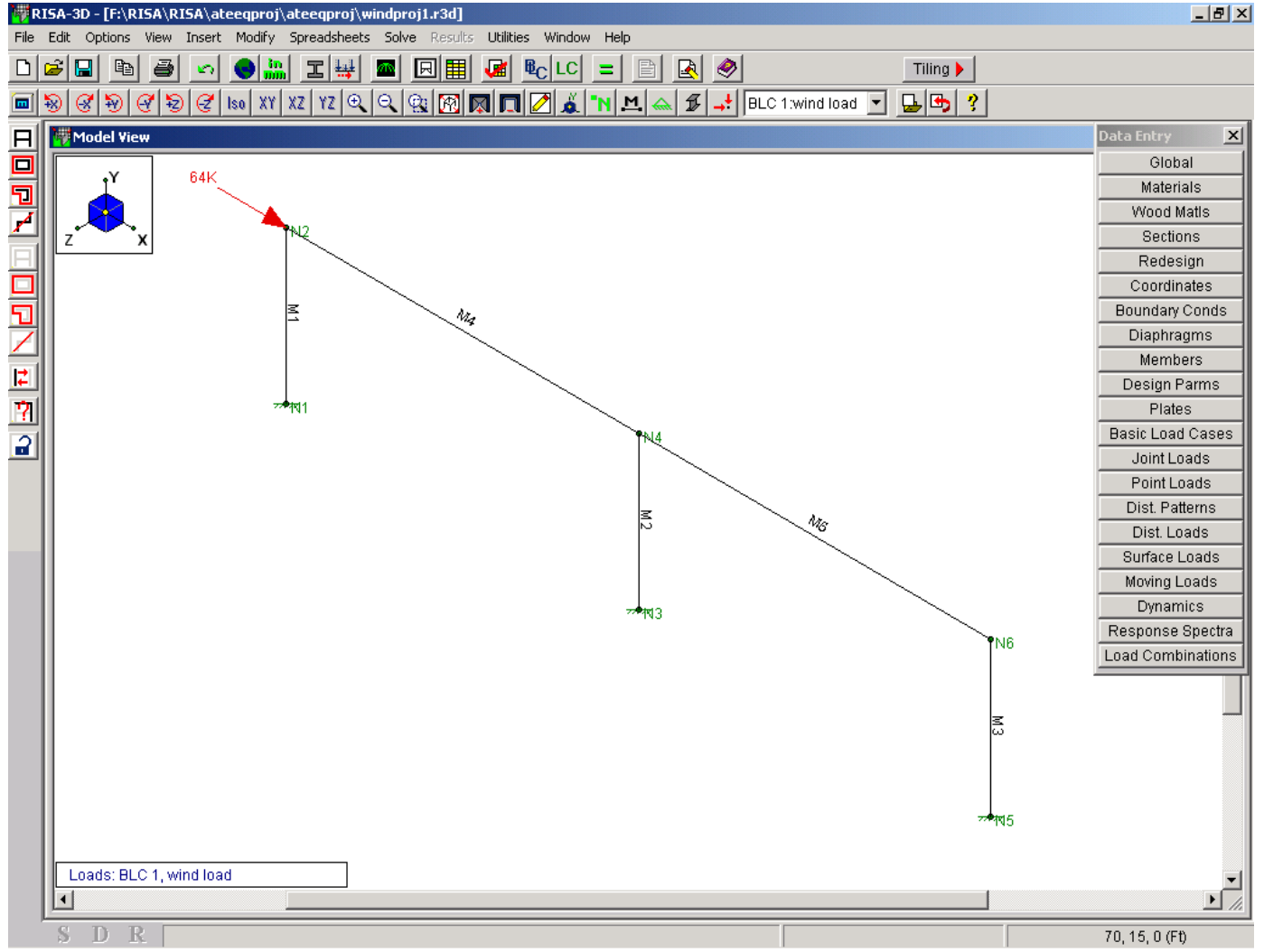

Figure 4. Basic Frame with Concentrated Wind Load. 


\subsection{Case 3: Distributed Load and Two Braces}

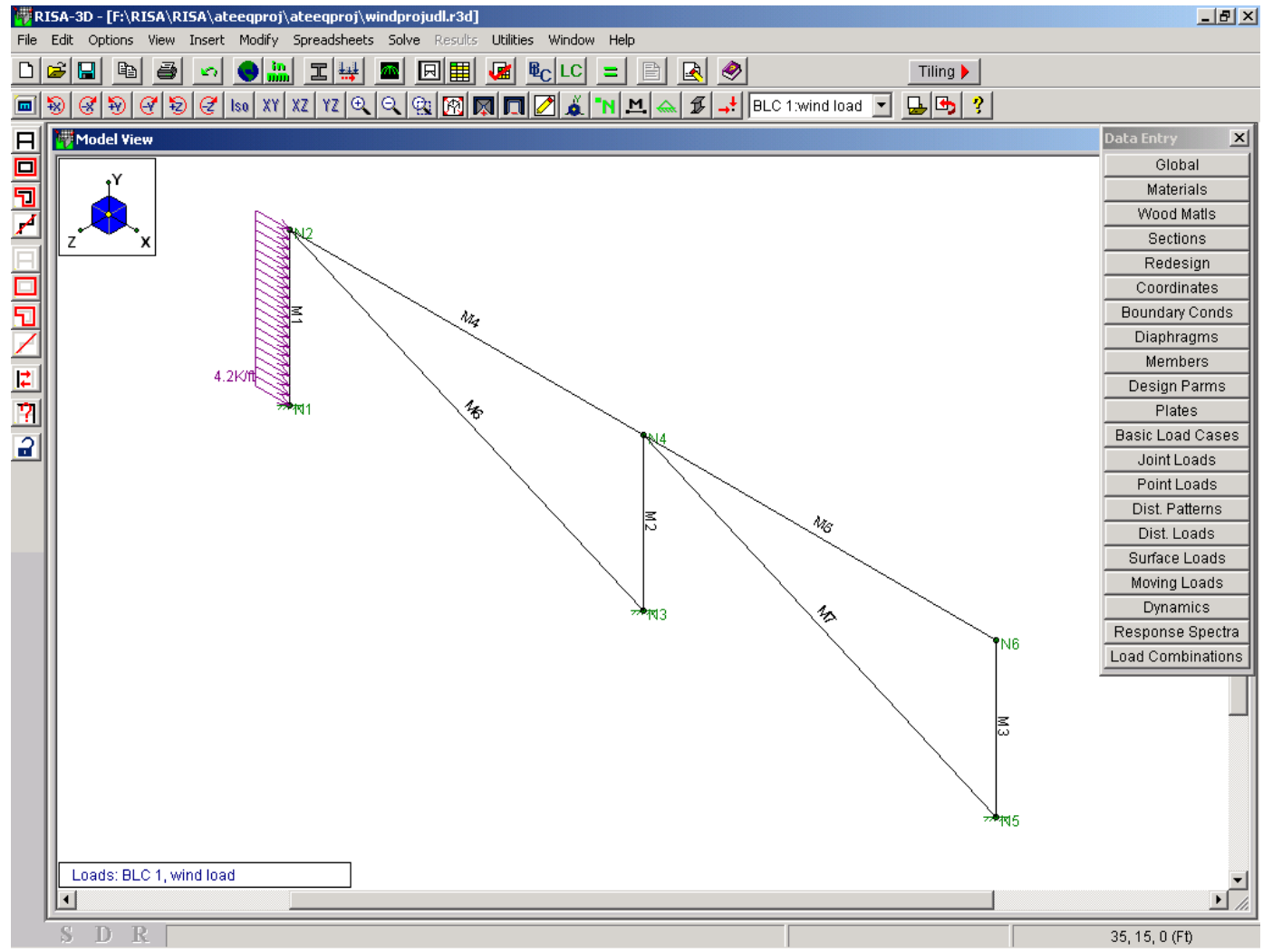

Figure 5. Basic Frame with Two Braces and Uniformly Distributed Wind Load.

\subsection{Case 4: Concentrated Load and Two Braces}

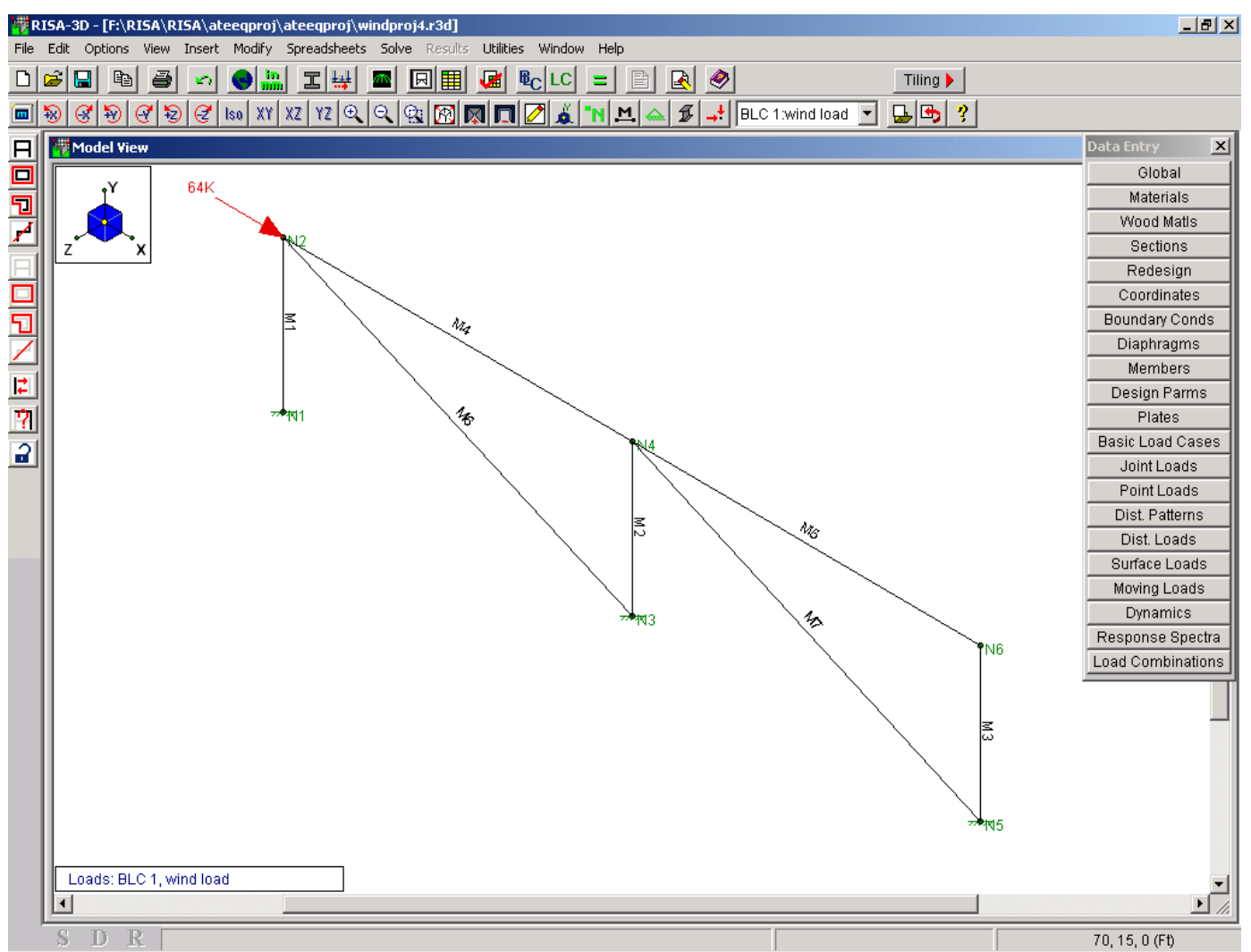

Figure 6. Basic Frame with Two Braces and Concentrated Wind Load. 


\subsection{Case 5: Distributed Load and Four Braces}

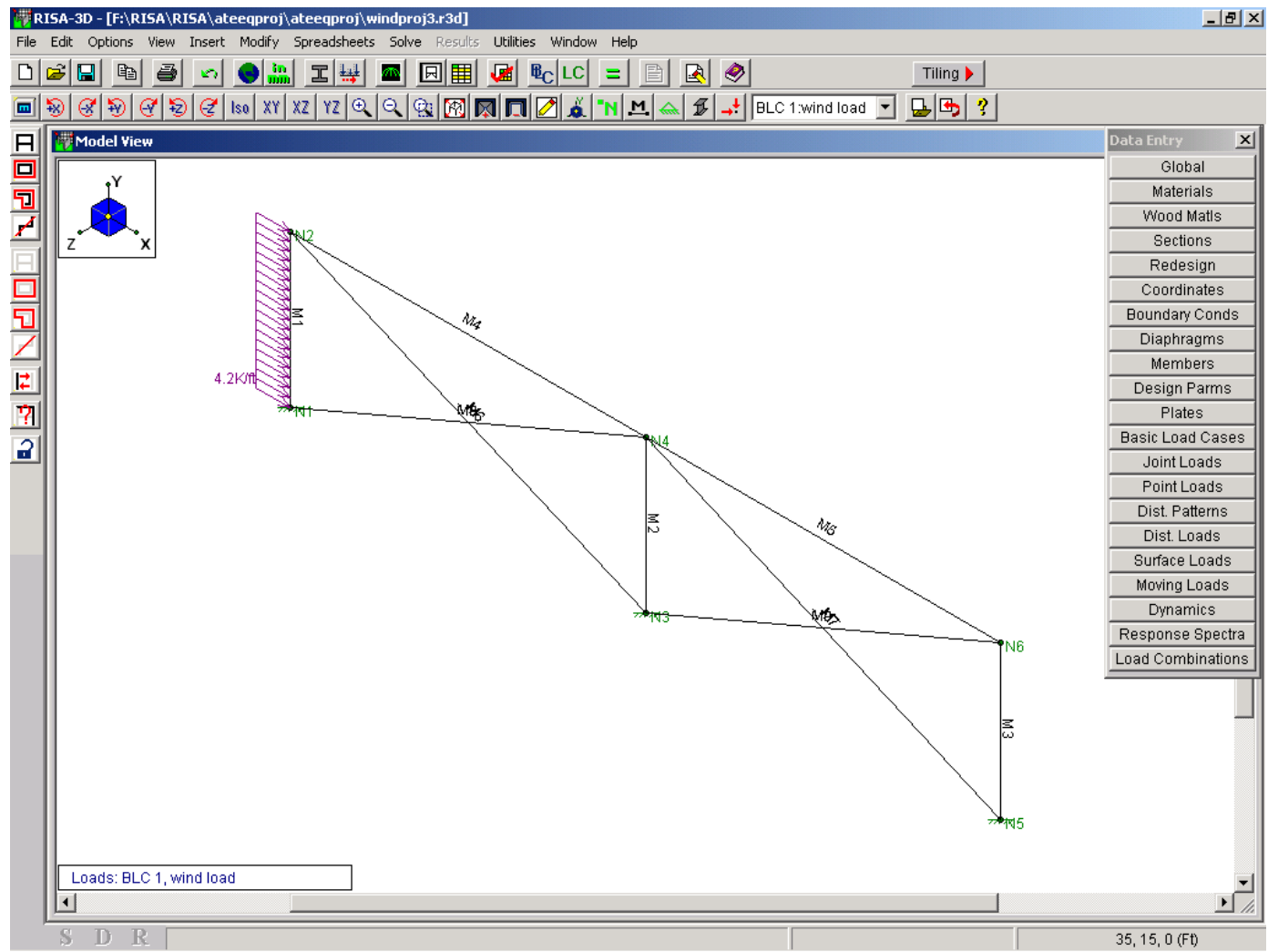

Figure 7. Basic Frame with Four Braces and Uniformly Distributed Wind Load.

\subsection{Case 6: Concentrated Load and Four Braces}

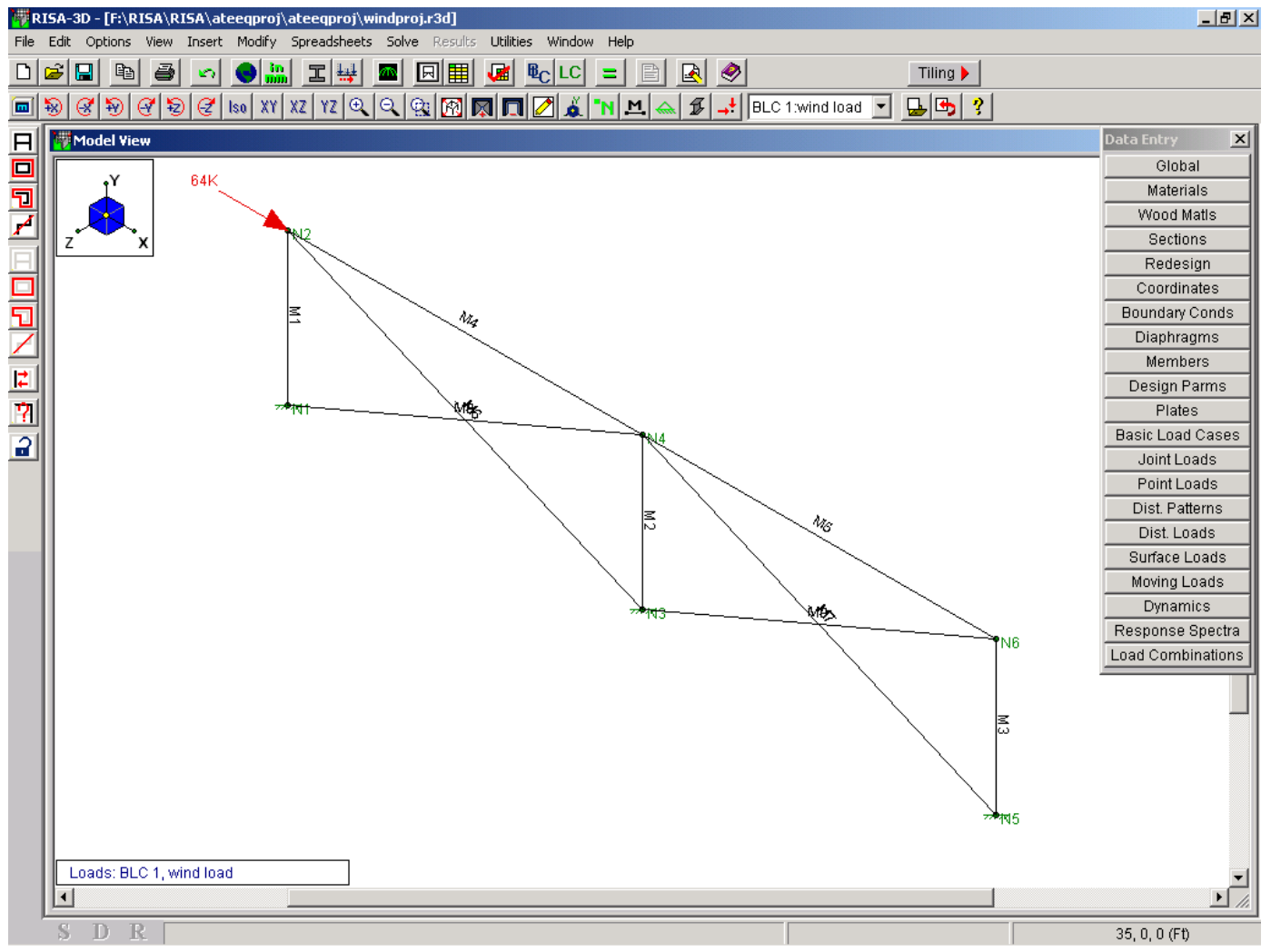

Figure 8. Basic Frame with Four Braces and Concentrated Wind Load. 


\subsection{Comparison of Results}

The above cases provided us with valuable information. Moments and deflections for critical members are provided in Figures 9 through 12 for comparison purposes.

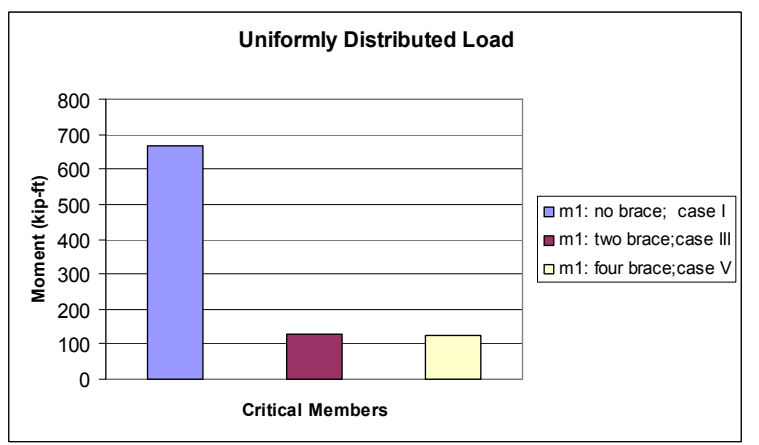

Figure 9. Comparison of Critical Moments; A Case of Uniformly Distributed Load.

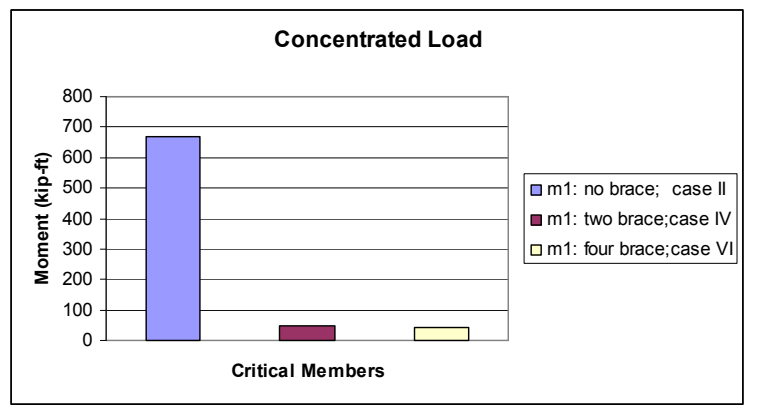

Figure 10. Comparison of Critical Moments; A Case of Concentrated Load.

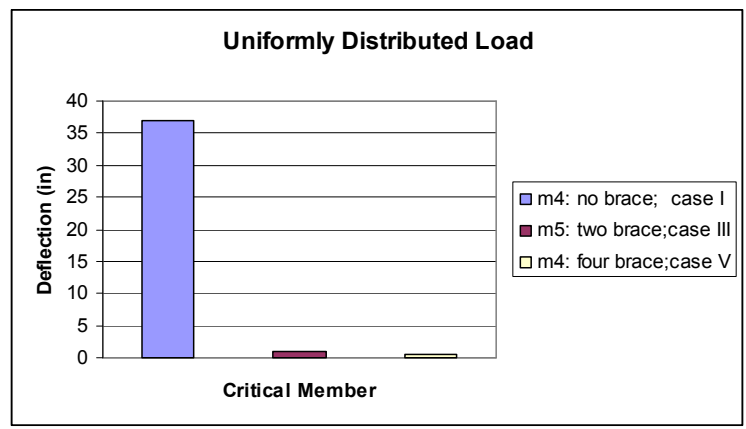

Figure 11. Comparison of Critical Deflection; A Case of Uniformly Distributed Load.

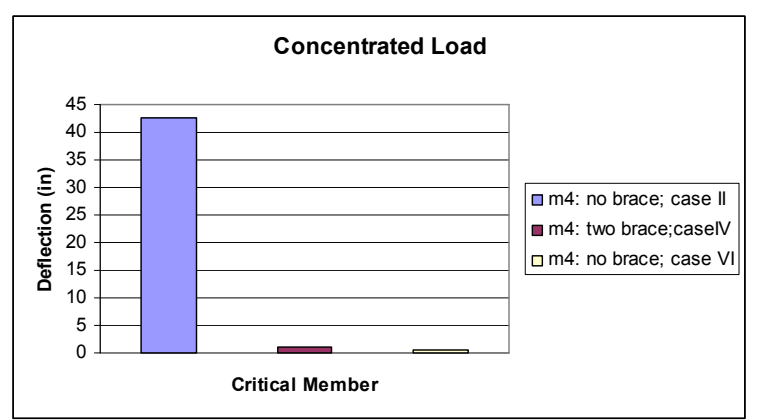

Figure 12. Comparison of Critical Deflections; A Case of Concentrated Load.
The results show that the member M1 with no brace (case I) has the largest moment (669 k-ft). This is because the wind is impacting the member directly, and it resists most of the impact. Accordingly, it produces the largest moment. Member M1 with four braces produced the smallest moment $(13.3 \mathrm{k}-\mathrm{ft})$. The braces seem to resist the force. Further, the deflection results show that M4 with no brace has the highest deflection (42.6 in), while M4 with four braces (case V) has the least induced deflection $(0.497 \mathrm{in})$. This is because the braces resist the force induced by the wind and accordingly reduce the deflection in the member.

\section{Conclusions}

The main goal of this basic work was to analyze a typical shopping center located in South Texas subjected to hurricane intensity loads using RISA-3D [11] along with the combination of design specifications from American Society of Civil Engineers (ASCE) [12] and American Institute of Steel Construction-Load-Resistance and Factor Design (AISC-LRFD) [13]. The analysis helped identify critical members and may be useful in producing better hurricane resistant design. A total of six loading cases were studied in this project namely: uniformly distributed and concentrated loads with no brace, two braces and four brace combinations. The following limited conclusions were obtained from this work:

1) Member M1 with no brace and four braces respectively produced the largest and smallest moments; and

2) Member M4 with no brace and four braces respectively produced the highest and lowest deflections.

\section{Future Work}

Further research is possible in this topic by applying different conditions, materials and studying different types of structures. For example, effect of hurricane intensity wind loads on single-story and multi-story concrete buildings may be a possibility.

\section{References}

[1] Nur Yazdani et al, (2004), "Large Wind Missile Impact Performance of Public and Commercial Building Assemblies." Florida Department of Community Affairs, Division of Emergency Management.

[2] Cangialosi, J. P., et al, (2018), "National Hurricane Center Tropical Cyclone Report: Hurricane Irma," National Oceanic and Atmospheric Administration.

[3] Montz, B. E., et al, (2017), "Natural Hazards, Second Edition: Explanation and Integration," Second Edition, Guilford Publications.

[4] Berg, R., (2018), "National Hurricane Center Tropical Cyclone Report: Hurricane Jose," National Oceanic and Atmospheric Administration. 
[5] Pasch, R., et al, (2018), "National Hurricane Center Tropical Cyclone Report: Hurricane Maria," National Oceanic and Atmospheric Administration.

[6] Lin, N, and Emanuel, K., (2015), "A Model for the Complete Radial Structure of the Tropical Cyclone Wind Field. Part I: Comparison With Observed Structure." Journal of Atmospheric Science, Vol 72, pp. 3647-3662, https://doi.org/10.1175/JAS-D-15-0014.1.

[7] Lazarus, E. D., et al, (2018), "Building Back Bigger in Hurricane Strike Zones." Nature Sustainability, Vol 1, pp. 759-762, https://doi.org/10.1038/s41893-018-0185-y.

[8] Gavanski, E., et al, (2016), "Uncertainties in the Estimation of Local Peak Pressures on Low-Rise Buildings by GumbelFitting Approach.” Journal of Structural Engineering, Vol 142 (11), doi: 10.1061/(asce)st.1943-541x.0001556.

[9] Kopp, G. A., and Morrison, M. J., (2018), "Component and Cladding Wind Loads for Low-Slope Roofs on Low-Rise Buildings." Journal of Structural Engineering, Vol 144 (4), doi: 10.1061/10.1061/(asce)st.1943-541x.0001989.
[10] Schroeder, J. L., and Smith, D. A., (2003), "Hurricane Bonnie Wind Flow Characteristics," Journal of Wind Engineering and Industrial Aerodynamics, Vol 91, pp. 767-789.

[11] RISA 3D, (2006), "Rapid Interactive Structural Analysis User Guide," Version 6.0, Foothill Ranch, California.

[12] ASCE 7, (2002), "Minimum Design Loads for Buildings and Other Structure," American Society of Civil Engineers, Reston, Virginia.

[13] AISC, (2003), "Manual of Steel Construction (LRFD)," Third Edition, American Institute of Steel Constructon, Chicago, Illinois.

[14] National Weather Service, (2006), "Saffir-Simpson Scale for Hurricane Categories," retrieved from https://www.weather.g ov/mfl/saffirsimpson.

[15] Pan American Health Organization, (2005), "Disaster Mitigation in Health Facilities: Wind Effects Structural Issues," Regional Office of World Health Organization, Dominican Republic. 